\title{
KONTROVERSEN UND POLEMIK IN SPRACHE, LITERATUR UND KULTUR
}

Kontroversen und umstrittene Themen, strittige Fragestellungen und die damit verbundene Polemik begleiten uns seit eh und je. Verschiedenartige Auseinandersetzungen begegnen auf jeder Ebene menschlicher Tätigkeit. Nicht zuletzt sind es akademische Dispute samt den auf deren Basis entstandenen wissenschaftlichen Publikationen, die ohne Zweifel oft dazu beitragen, den aktuellen Wissensstand zu erweitern bzw. ihn zu verifizieren. Nicht selten finden die Polemiken nicht nur innerhalb der veröffentlichten Texte statt - auch die an ihnen interessierten Empfänger werden mehr oder weniger Teil der Diskussion, was zu einer von den Wissenschaftlern so begehrten Weiterentwicklung des Meinungsaustausches führen kann. Und in der Polemik, Gadamer paraphrasierend, hat doch niemand das letzte Wort...

Im vorliegenden Band der Folia Germanica findet man Beiträge aus dem Bereich der Linguistik, Literaturwissenschaft und Geschichte, die zweifelsohne den Leser polemisch anmuten werden.

Wir laden Sie gerne zur Mitarbeit ein. Alle brauchbaren Informationen zur Manuskriptgestaltung sowie zum jeweils aktuellen Dachthema des Bandes finden Sie auf unserer Homepage unter www.foliagermanica.uni.lodz.pl.

Wir wünschen Ihnen eine aufschlussreiche und polemikreiche/polemische Lektüre.

Die Herausgeber 